\title{
Mental Health in Young Healthcare and Social Work Professionals: Associations with Psychosocial Work Environment Factors
}

Tore Bonsaksen ( $\nabla$ tore.bonsaksen@gmail.com )

OsloMet - storbyuniversitetet Fakultet for helsefag https://orcid.org/0000-0001-6315-1111

\section{Per Nerdrum}

OsloMet - storbyuniversitetet

Amy Østertun Geirdal

OsloMet - storbyuniversitetet Fakultet for samfunnsvitenskap

\section{Research article}

Keywords: general health questionnaire, mental health, nursing, occupational therapy, professions, physiotherapy, psychological distress, social work, work environment

Posted Date: July 16th, 2020

DOI: https://doi.org/10.21203/rs.3.rs-39706/v1

License: (c) (i) This work is licensed under a Creative Commons Attribution 4.0 International License. Read Full License 


\section{Abstract}

Background: Associations between work environment factors and mental health may differ between groups. The study aimed to explore associations between aspects of the psychosocial work environment and mental health among young professionals in four healthcare and social work groups in Norway.

Methods: 856 employees were included in this cross-sectional study six years after graduation. The participants completed questionnaires concerned with mental health, work environment, work engagement, and psychological work factors. Data were analyzed with linear and logistic regression analyses.

Results: In the whole sample, poorer mental health was associated with higher demands, lower support, lower job satisfaction, more work-home interaction problems, and lower coping in the job. Each unit increase in work-home interaction problems doubled the likelihood of having case-level psychological distress. The strength of the associations between mental health and other factors, such as the demands and support experienced in the job and perceived coping in the job, varied by professional group.

Conclusions: Problems concerned with the interaction between work and home were generally associated with poorer mental health. Between professional groups, other independent variables were differently associated with mental health. Work environment factors should receive continued attention in efforts to investigate and promote mental health.

\section{Background}

The interplay between various forces create, sustain and challenge mental health. Common environmental risk factors for poor mental health concern interpersonal, economic and socio-structural factors [1]. These factors include unemployment and financial insecurity [2], loneliness, bullying and interpersonal conflict [3-5] and stressful life events and trauma, such as assault, rape and war, losing a job, or the death of a close family member or friend [5-8].

With regards to sociodemographic characteristics, women have higher prevalence of all mental disorders than men, with the exception of substance use disorders, for which the prevalence is twice as high among men $[9,10]$. Young adults ( $<34$ years) have been found to have twice as high 12-month prevalence of mental disorders, compared to older adults (>65 years) $[10,11]$. Amongst young adults, university students' mental health has received increasing attention over the last years. National $[12,13]$ and international [14] studies and reports alike have documented substantial and increasing mental health problems among university students. Other studies have found students' low level of help-seeking to be a more pressing concern [15].

Students' mental health and its development over time appear to differ between professional groups. A longitudinal study from Norway found that nursing students' mental health was worsened during the course of the education program, whereas no significant changes was shown for students of 
occupational therapy and physiotherapy [16]. Similarly, between graduation and three years after, healthcare professionals (nurses, occupational therapists and physiotherapists) improved their mental health significantly, while the trend of improvement was not statistically significant for teachers and social work professionals [17].

For young professional employees, aspects of the psychosocial work environment seem to be of importance for their mental health. Several studies and reviews have found that that high-strain jobs, characterized by low employee control and high demands, are associated with lower well-being and higher stress levels [18-23] and also associated with sick leave from work [24-28]. However, employees' attitudes towards the job is also of importance for their well-being. While involvement in work and productive activity is in line with the World Health Organization's definition of mental health [29], overinvolvement in work may produce poorer mental health (Niedhammer et al., 2006). In a recent example, Skogen and co-workers [30] found that employees with high ratings on 'overcommitment to work', in particular when combined with high imbalance between perceived efforts and rewards in the job, had higher odds of having alcohol-related problems, compared to employees with lower overcommitment.

In view of the evidence, the notion that the psychosocial work environment is important for employees' mental health is well established. In addition, different trajectories of mental health between professional groups during the first years in their professional careers suggest that associations between work environment factors and mental health may differ between groups of employees. Thus, the aim of this study was to explore the associations between aspects of the psychosocial work environment and mental health among young professionals in four healthcare and social work groups in Norway.

\section{Method}

\section{Design and data collection}

The data were extracted from the STUDDATA database [16], a database containing self-report data from a range of professional groups over a nine-year period. For the current study, a cross-sectional design was employed in the exploration of associations between psychosocial work environment factors and mental health in four groups of healthcare- and social work professionals six years after graduation. Thus, the sample is a group of professionals assumed to be well established in their respective fields of practice, yet relatively early in their career as health and social care professionals. The participants were recruited from six different Norwegian higher education institutions, with the majority from Oslo.

\section{Measures}

\section{Sociodemographic variables}

The demographic variables used in the present study were age in years (continuous) and gender (male and female). None of the employed research measurements, as described in the following, are under 
license.

\section{Work environment factors}

Based on Karasek's [31] Job Demands and Control (JDC) model, three variables are constructed based on responses to the Job Content Questionnaire [JDQ; 32]. The instrument has been used in a range of national and international studies of psychosocial work environment factors [e.g., 17, 22, 33, 34].

Demands refer to the work pressure and the workload experienced in the job, and was measured with five items (Cronbach's a $=0.77)$ Control, sometimes coined decision latitude, refers to the level of control the employee has over decisions that are important to his work, as well as the possibility of developing and using personal skills in the job. This variable was measured with nine items (Cronbach's $a=0.75$ ). Support concern the perceived support from both supervisors and colleagues at work and was measured with four items (Cronbach's a $=0.79$ ). Higher scores indicate higher demands, control and support, respectively.

\section{Work engagement}

Job involvement

Job involvement is defined as the degree to which a person's work performance affects his or her selfesteem [35]. The 6-item version of the Job Involvement Scale [36] was used to measure job involvement, and higher total score indicates lower involvement. Cronbach's $a=0.70$, which indicates that the internal consistency was acceptable in this sample.

Job satisfaction

To assess job satisfaction, the 14-item version of the Work Orientations II Module was included [37]. The 14 items are linked to paid work and evaluate the individual's satisfaction with seven aspects of their present job; job security, high income, good advancement opportunities, an interesting job, a job that allows someone to work independently, a job that allows someone to help other people and a job that is useful to society [38-40]. Higher scores indicate lower overall satisfaction with the job. Cronbach's a for the scale was 0.73 .

\section{Psychological work factors}

QPS $_{\text {Nordic }}$

The General Nordic Questionnaire for Psychological and Social Factors at Work (QPS ${ }_{\text {Nordic }}$ ) measures psychological and social aspects at work [41]. The instrument has been used in several large-scale projects [42], and has shown good psychometric properties [43]. QPS ${ }_{\text {Nordic }}$ measures different aspects using two-item subscales, among them work-home interaction (whether the job affects private life negatively, or vice versa; inter-item correlation $=0.43$ ), coping in the job (inter-item correlation $=0.51$ ) and collaboration with co-workers (inter-item correlation $=0.29$ ), and these three aspects were included in this 
study. Higher scores indicate more work-home interaction problems, better coping in the job, and better collaboration with co-workers.

\section{Mental health}

The 12-item General Health Questionnaire (GHQ-12) is widely used as a self-report measure of mental health $[44,45]$. A large number of studies in the general adult population, clinical populations, work populations and student populations have provided support for its validity across samples and contexts [45-49]. Six items of the GHQ-12 are phrased positively (e.g. 'able to enjoy day-to-day activities'), while six items are phrased as a negative experience (e.g. 'felt constantly under strain'). On each item, the person indicates the degree to which the item content has been experienced during the two preceding weeks, using four response categories ('less than usual', 'as usual', 'more than usual' or 'much more than usual'). Items are scored between 0 and 3 , and positively formulated items are recoded prior to analysis. As a result, the GHQ-12 scale score range is $0-36$, with higher scores indicating poorer mental health (more psychological distress). In this study, Cronbach's a for the 12 scale items was 0.86 . Case-level scores (the person indicating 'more than usual' or 'much more than usual' on at least four of the 12 items) indicate a level of psychological distress where treatment may be needed [50].

\section{Statistical analysis}

Continuous variables were described with means $(M)$ and standard deviations $(S D)$, categorical data with counts and percentages within groups. Group differences regarding age and psychosocial work environment factors were examined with one-way analysis of variance (ANOVA), adjusted by the Bonferroni correction, and with Chi-square test for gender proportions.

Crude and adjusted associations with mental health (GHQ continuous measure) were examined with single and multiple linear regression analysis. Variables with a statistically significant bivariate association with the GHQ score in the total sample were included in the adjusted analyses for all groups. Standardized $\beta$ values were used as effect size and interpreted according to Cohen [51], differentiating between small ( 0.30 or lower), medium ( $0.31-0.50)$ and large ( 0.51 or higher) effect sizes. Crude and adjusted associations with case-level psychological distress (GHQ categorical measure) were examined with binary logistic regression analysis. Variables with a statistically significant bivariate association with case-level psychological distress in the total sample were included in the adjusted analyses for all groups. Odds ratio (OR) was used as effect size, and the $95 \%$ confidence interval $(95 \% \mathrm{Cl})$ of the OR was reported. The analyses were performed for the total sample and for each of the professional groups separately. Results with a corresponding $p$-value lower than 0.05 were interpreted as statistically significant.

\section{Ethics approval and informed consent}

All participants provided signed informed consent and were informed that participation in the study was voluntary and that their consent to participate could be withdrawn at any time. As the primary purpose of 
the parent study, from which the data was gathered, was not related to health, approval of this sub-study from the regional committee for medical and healthcare research ethics was not required (https://lovdata.no/dokument/NL/lov/2008-06-20-44). Permission to collect, use and store the data was obtained from the Norwegian Data Protection Official for Research.

\section{Results}

\section{Participant characteristics}

In total, 856 persons were included in the study. Of these, 386 (45.1\%) were nurses, $84(9.8 \%)$ were occupational therapists, 157 (18.3\%) were physiotherapists, and 229 (26.8\%) were social workers. A summary of the sample characteristics is displayed in Table 1. There were statistically significant group differences with regards to age (mean age ranging between 37 years for social workers and 32 years for physiotherapists) and gender (proportion of females ranging between $92 \%$ for nurses and $76 \%$ for physiotherapists). Further, group differences were significant with regards to demands (nurses with highest scores, physiotherapists with lowest scores), control (nurses with lowest scores, physiotherapists with highest scores) and support (nurses with lowest scores, physiotherapists with highest scores). There were no significant group differences regarding levels of mental health (mean GHQ score ranging between 10.0 [physiotherapists] and 11.0 [occupational therapists]), nor regarding proportions with caselevel psychological distress (proportions ranging between 16\% [physiotherapists] and 19\% [social workers]).

\section{[TABLE 1 ABOUT HERE]}

\section{Associations With Mental Health}

Age, gender and job involvement did not show a significant bivariate association with the continuous GHQ score and were therefore not included in the subsequent linear regression analysis. For the total sample, the multiple regression analysis (displayed in Table 2) showed that poor mental health was significantly associated with higher demands and lower support at work, lower job satisfaction, more work-home interaction problems, and lower coping in the job. Among the nurses and physiotherapists, poor mental health was significantly associated with more work-home interaction problems and lower coping in the job. Among the occupational therapists, poor mental health was significantly associated with higher demands at work and more work-home interaction problems. Among the social workers, poor mental health was significantly associated with higher demands and lower support at work. More of the $\mathrm{GHQ}$ variance was explained by the employed independent variables for the occupational therapists (31.9\%), compared to the other professional groups $(16.0 \%-21.4 \%)$.

[TABLE 2 ABOUT HERE] 


\section{Associations With Case-level Psychological Distress}

Age, gender, control, support, job involvement, coping in the job and collaboration did not show significant bivariate associations with case-level GHQ score, and these variables were therefore not included in the subsequent multiple logistic regression analysis. For the total sample, the multiple logistic regression model (displayed in Table 3) showed that higher odds of having case-level psychological distress was significantly associated with higher job demands, lower job satisfaction and more work-home interaction problems. For the nurses, higher odds of case-level psychological distress were significantly associated with lower job satisfaction and more work-home interaction problems. For the occupational therapists in particular, but also for the physiotherapists, higher odds of case-level psychological distress were significantly associated with more work-home interaction problems. For the social workers, higher odds of case-level psychological distress were significantly associated with higher job demands.

[TABLE 3 ABOUT HERE]

\section{Discussion}

This study aimed to explore the associations between aspects of the psychosocial work environment and mental health among young professionals in four healthcare and social work groups in Norway. Six years after graduation, the levels of mental health were not significantly different between the participating nurses, occupational therapists, physiotherapists and social workers. A range of work environment and psychosocial factors at work were significantly associated with mental health in the sample. However, rerunning the analyses for each professional group demonstrated both similarities as well as differences with regards to the factors of importance for mental health.

Sustaining mental health is one of the major challenges for public health globally [52], with reports of $17.6 \%$ of the global population experiencing a common mental disorder during the last year and $29.2 \%$ having experienced a common mental disorder during the lifetime [53]. Using the GHQ in the current study, the prevalence of $17.2 \%$ (range $15.9 \%-18.8 \%$ ) for case-level psychological distress appears to reflect well the global estimates of common mental disorders. In the Norwegian general population, recent prevalence estimates for current self-reported mental disorders have been found to be $6.6 \%$ for anxiety [54] and $8.1 \%$ for depression [55], while having anxiety and/or depression - largely comparable to the concept of psychological distress - was found among $14.1 \%$ of the sample. In line with previous studies [50,56,57], these results provide additional support for the GHQ as a relevant screening instrument for mental health problems. The results also indicate similar levels of mental health among participants in the four professional groups, and similar proportions of persons with case-level psychological distress.

For the whole sample, several associations were found between individual predictors and mental health. Case-level psychological distress was associated with higher psychological demands in the work, lower job satisfaction and higher levels of work-home interaction problems. The same factors, in addition to 
lower support and lower coping in the job, were associated with poorer mental health when mental health was measured on the continuous GHQ scale. These findings appear logical and are generally consistent with previous research [18, 19, 22, 23, 58]. However, according to Cohen [51], the strength of the associations were relatively weak overall $(\beta \leq 0.22)$, which is logical given that the effect sizes for the total sample averages the effects for the participants across professional groups. A notable exception is the finding for work-home interaction problems, for which a one-unit increase in scale ratings more than doubled the risk of experiencing case-level psychological distress. Thus, the overall findings suggest that problems in managing and balancing the demands at work with those at home is a powerful predictor for mental health problems among young professional employees.

Among the work environment factors significantly associated with mental health, some were common across several professional groups, while others were found to be more profession specific. While workhome interaction problems were significantly associated with poorer mental health for nurses, physiotherapists and - in particular - for occupational therapists, this association was not significant for social workers. Instead, for the social workers, the demand and support variables introduced by Karasek and Theorell [31] were systematically associated with their mental health. This is partly in accordance with the findings from the three-year follow up, where higher ratings on demand were associated with poorer mental health in this group [17]. For the social workers, therefore, higher demands appear to predict poorer mental health consistently over the first six years in professional practice. The possibility of reducing work demands and increasing the support between co-workers and between employees and managers may have the potential to improve social workers' mental health.

For nurses and physiotherapists, coping in the job was also directly associated with better mental health (in addition to the already discussed association between work-home interaction problems and mental health). This might reflect higher levels of identification with the job among nurses and physiotherapists, compared to occupational therapists and social workers. Possibly, the finding may indicate that nurses and physiotherapists invest more of their self-esteem into their work. If so, experiencing problems in the job and feeling dissatisfied with one's own work may make nurses and physiotherapists more inclined to react with psychological symptoms, compared to professional groups where self-esteem is less strongly related to the work experience. This reasoning concerned with self-esteem contingencies; i.e., the circumstances under which self-esteem relates more strongly to behaviors or performance, has been supported in theory [59] and previous studies $[60,61]$. In line with this interpretation, improving mental health among nurses and physiotherapists may include relying more on sources of self-esteem other than their work performance.

Consistent with the results for most of the professional groups, occupational therapists' mental health was strongly associated with work-home interaction problems. In fact, one unit increase on this scale five times increased the likelihood of being classified with case-level psychological distress. Like the results for the social workers, and consistent with several research studies [e.g., 19, 23] higher demands in the job were also associated with poorer mental health among occupational therapists. Thus, among the work environment factors investigated in this study, reducing work demands and reducing work-home 
interaction problems appear to have potential to improve mental health among occupational therapists. While it can be difficult for managers and occupational health services to directly assist occupational therapists in adjusting their work-home interaction, they can be vigilant towards occupational therapists' perception of job demands. Possibly, reducing job demands may also translate into a better balance between the demands at work and at home, which in turn may improve mental health.

As the prediction models were equal across groups, it was possible to compare the proportions of explained outcome variance between the groups. This study demonstrated that the employed work environment variables accounted for a greater proportion of the variance in mental health among occupational therapists (31.9\%), compared to nurses, physiotherapists and social workers $(16.0 \%$ $21.4 \%)$. Therefore, while assessing the work environment in relation to mental health is relevant for all the groups investigated in this study, it appears to be particularly useful when investigating the mental health of occupational therapists.

\title{
Study Limitations And Future Research
}

As this study employed a sample that was relatively modest in size, especially when used in the subgroup analyses ( $n$ ranging between 84 and 386), future studies may preferably ensure that group sizes are large enough to be representative of the part population. The representativity of the sample groups used in this study is difficult to verify. The cross-sectional nature of the employed data renders it impossible to verify causal attributions, and reversed causality is in some cases probable. For example, poor mental health may cause lower coping in the job, as well as the oppositely directed association. In the future, longitudinal studies, especially studies involving some form of work environment intervention, may potentially clarify the nature of some of the associations revealed in this study.

\section{Conclusion}

The aim of this study was to explore the associations between aspects of the psychosocial work environment and mental health among young professionals in four healthcare and social work groups in Norway. For three of the four groups, problems concerned with the interaction between work and home significantly predicted poorer mental health. The strength of the associations between mental health and other factors, such as the demands and support experienced in the job and perceived coping in the job, varied by professional group. For occupational therapists, the employed work environment factors accounted for a substantial proportion of the variance in mental health, and they should therefore receive continued attention in efforts to investigate and promote mental health.

\section{Abbreviations}

\author{
ANOVA
}

Analysis of variance

$\mathrm{Cl}$ 
Confidence interval

JCQ

Job Content Questionnaire

JDC

Job Demands Control model

GHQ

General Health Questionnaire

$\mathrm{M}$

Mean

OR

Odds ratio

QPS Nordic

Nordic questionnaire for psychological and social factors at work

SD

Standard deviation

STUDDATA

The database from which the data used in this study were extracted

\section{Declarations}

\section{Ethics approval and consent to participate}

All participants provided signed informed consent and were informed that participation in the study was voluntary and that their consent to participate could be withdrawn at any time. Approval from the regional committee for medical and healthcare research ethics was not required

(https://lovdata.no/dokument/NL/lov/2008-06-20-44). The study was granted permission to collect, use and store the data by the Norwegian Data Protection Official for Research.

\section{Consent for publication}

Not applicable

\section{Availability of data and materials}

The data analysed during the current study are available from the corresponding author on reasonable request.

\section{Competing interests}

The authors declare that they have no competing interests

\section{Funding}


The study received no funding

\section{Authors contributions}

$T B, P N$ and $A \varnothing G$ contributed to the study design and idea. TB performed the statistical analysis and drafted the manuscript. $P N$ and $A \emptyset G$ contributed critical revisions to the manuscript. TB, PN and $A \varnothing G$ approved of the final submitted version.

\section{Acknowledgements}

The authors thank all participants for contributing their time to the STUDDATA investigation.

\section{References}

1. Bronfenbrenner U. Ecology of the family as a context for human development: research perspectives. Dev Psychol. 1986;22:723-42.

2. Gili M, Roca M, Basu S, McKee M, Stuckler D. The mental health risks of economic crisis in Spain: evidence from primary care centres, 2006 and 2010. Eur J Public Health. 2013;23:103-8.

3. Segrin C. Interpersonal processes in psychological problems. New York: Guildford; 2001.

4. Kendler KS, Hettema JM, Butera F, Gardner CO, Prescott CA. Life event dimensions of loss, humiliation, entrapment, and danger in the prediction of onsets of major depression and generalized anxiety. Arch Gen Psych. 2003;60:789-96.

5. Norwegian Institute of Public Health. Mental illness among adults. Oslo: Norwegian Institute of Public Health; 2016.

6. Kendler KS, Gardner CO. Depressive vulnerability, stressful life events and episode onset of major depression: a longitudinal model. Psychol Med. 2016;46(9):1865-74.

7. Amstadter AB, Aggen SH, Knudsen GP, Reichborn-Kjennerud T, Kendler KS. Potentially traumatic event exposure, posttraumatic stress disorder, and Axis I and II comorbidity in a population-based study of Norwegian young adults. Soc Psych Psychiatr Epidemiol. 2013;48:215-23.

8. Schou-Bredal I, Bonsaksen T, Ekeberg $\varnothing$, Skogstad L, Grimholt T, Lerdal A, Heir T. Sexual assault and the association with health, quality of life and self-efficacy in the general Norwegian population (in press). $J$ Interpers Violence 2020.

9. Rehm J, Shield KD. Global burden of disease and the impact of mental and addictive disorders. Curr Psych Rep. 2019;21:10.

10. Alonso J, Angermeyer MC, Bernert S, Bruffaerts R, Brugha TS, Bryson H, de Girolamo G, Graaf R, Demyttenaere K, Gasquet I, et al. Prevalence of mental disorders in Europe: results from the European Study of the Epidemiology of Mental Disorders (ESEMeD) project. Acta Psychiatr Scand Suppl 2004(420):21-7.

11. Jacobi F, Hofler M, Strehle J, Mack S, Gerschler A, Scholl L, Busch MA, Hapke U, Maske U, Seiffert I, et al. Twelve-months prevalence of mental disorders in the German Health Interview and Examination 
Survey for Adults - Mental Health Module (DEGS1-MH): a methodological addendum and correction. Int J Methods Psychiatr Res. 2015;24:305-13.

12. Nedregård T, Olsen R. Student's Health and Wellbeing Study 2014. Oslo: TNS Gallup; 2014.

13. Sivertsen B, Råkil H, Munkvik E, Lønning KJ. Cohort profile: the SHoT-study, a national health and well-being survey of Norwegian university students. BMJ Open. 2019;9(1):e025200.

14. Eagan K, Stolzenberg EB, Ramirez JJ, Aragon MC, Suchard MR, Hurtado S. The American freshman: National norms fall 2014. Los Angeles: Higher Education Research Institute, UCLA 2014.

15. Macaskill A. The mental health of university students in the United Kingdom. Br J Guid Couns. 2013;41:426-41.

16. Nerdrum P, Rustøen T, Rønnestad MH. Psychological distress among nursing, physiotherapy and occupational therapy students: A longitudinal and predictive study. Scand J Educ Res. 2009;53:36378.

17. Geirdal A, Nerdrum P, Bonsaksen T. The transition from university to work: what happens to mental health? A longitudinal study. BMC Psychol. 2019;7:65.

18. Netterstrøm B, Conrad N, Bech P, Fink P, Olsen O, Rugulies R, Stansfeld S. The Relation between Workrelated Psychosocial Factors and the Development of Depression. Epidemiol Rev. 2008;30:118-32.

19. Stansfeld S, Candy B. Psychosocial work environment and mental health-a meta-analytic review. Scand J Work Environ Health. 2006;32:443-62.

20. Duijts SF, Kant I, Swaen GM, Brandt PA, Zeegers MP. A meta-analysis of observational studies identifies predictors of sickness absence. J Clin Epidemiol. 2007;60:1105-15.

21. Zeike S, Ansmann L, Lindert L, Samel C, Kowalski C, Pfaff H. Identifying cut-off scores for job demands and job control in nursing professionals: a cross-sectional survey in Germany. BMJ Open. 2018;8(12):e021366.

22. Häusser JA, Mojzisch A, Niesel M, Schulz-Hardt S. Ten years on: A review of recent research on the Job Demand-Control (-Support) model and psychological well-being. Work Stress. 2010;24:1-35.

23. Nieuwenhuijsen K, Bruinvels D, Frings-Dresen M. Psychosocial work environment and stress-related disorders, a systematic review. Occup Med. 2010;60:277-86.

24. Mortensen J, Dich N, Lange T, Alexanderson K, Goldberg M, Head J, Kivimaki M, Madsen IE, Rugulies $\mathrm{R}$, Vahtera J, et al. Job strain and informal caregiving as predictors of long-term sickness absence: A longitudinal multi-cohort study. Scand J Work Environ Health. 2017;43:5-14.

25. Kondo K, Kobayashi Y, Hirokawa K, Tsutsumi A, Kobayashi F, Haratani T, Araki S, Kawakami N. Job strain and sick leave among Japanese employees: a longitudinal study. Int Arch Occup Environ Health. 2006;79:213-19.

26. Mather L, Bergstrom G, Blom V, Svedberg P. High Job Demands, Job Strain, and Iso-Strain are Risk Factors for Sick Leave due to Mental Disorders: A Prospective Swedish Twin Study With a 5-Year Follow-Up. J Occup Environ Med. 2015;57:858-65. 
27. de Vries H, Fishta A, Weikert B, Rodriguez Sanchez A, Wegewitz U. Determinants of Sickness Absence and Return to Work Among Employees with Common Mental Disorders: A Scoping Review. J Occup Rehabil. 2018;28:393-417.

28. Trybou J, Germonpre S, Janssens H, Casini A, Braeckman L, De Bacquer D, Clays E. Job-related stress and sickness absence among belgian nurses: a prospective study. J Nurs Scholar. 2014;46:292-301.

29. World Health Organization

Herrman H, Saxena S, Moodie R. World Health Organization. Promoting mental health: concepts, emerging evidence, practice: a report of the World Health Organization, Department of Mental Health and Substance Abuse in collaboration with the Victorian Health Promotion Foundation and the University of Melbourne. 2005.

30. Skogen JC, Thørrisen MM, Bonsaksen T, Vahtera J, Sivertsen B, Aas RW. Effort-Reward imbalance is associated with alcohol-related problems. WIRUS-screening study. Front Psychol 2019, 10(2079).

31. Karasek R, Theorell T. Healthy work: stress, productivity, and the reconstruction of working life. USA: Basic Books; 1990.

32. Karasek R, Brisson C, Kawakami N, Houtman I, Bongers P, Amick B. The Job Content Questionnaire (JCQ): an instrument for internationally comparative assessments of psychosocial job characteristics. J Occup Health Psychol. 1998;3:322-55.

33. Bonsaksen T, Thørrisen MM, Skogen JC, Aas RW. Who reported having a high-strain job, low-strain job, active job and passive job? The WIRUS Screening study. PLOS ONE. 2019;14(12):e0227336.

34. Sanne B, Mykletun A, Dahl AA, Moen BE, Tell GS. Testing the Job Demand-Control-Support model with anxiety and depression as outcomes: The Hordaland Health Study. Occup Med. 2005;55:46373.

35. Lodahl TM. Patterns of job attitudes in two assembly technologies. Admin Sci Quart. 1964;8:482519.

36. Lodahl TM, Kejnar M. The definition and measurement of job involvement. J Appl Psychol. 1965;49:24-33.

37. Kraut Al, Ronen S. Validity of job facet importance: A multinational multicriteria study. J Appl Psychol. 1975;60:671-7.

38. Hofstede G. Humanization of work: The role of values in the third industrial revolution. In: The humanization of work: a European perspective. Edited by Cooper CL, Mumford E. London: Associated Business Press; 1979: 18-37.

39. Hofstede G. Culture's consequences. Beverly Hills: Sage; 1980.

40. Hattrup K, Mueller K, Aguirre P. Operationalizing value importance in cross-cultural research: Comparing direct and indirect measures. J Occup Org Psychol. 2007;80:499-513.

41. Dallner M, Elo AL, Gamberale F, Hottinen V, Knardahl S, Lindström K, Skogstad A, Orhede E. Validation of the general nordic questionnaire (QPSNordic) for psychological and social factors at work. Vol. 12. Copenhagen: Nordic Council of Ministers; 2000. 
42. Björklund C, Grahn A, Jensen I, Bergström G. Does survey feedback enhance the psychosocial work environment and decrease sick leave? Eur J Work Org Psychol. 2007;16:76-93.

43. Wannstrom I, Peterson U, Asberg M, Nygren A, Gustavsson JP. Psychometric properties of scales in the General Nordic Questionnaire for Psychological and Social Factors at Work (QPS): confirmatory factor analysis and prediction of certified long-term sickness absence. Scand J Psychol. 2009;50:231-44.

44. Goldberg DP, Gater R, Sartorius N, Ustun TB, Piccinelli M, Gureje O, Rutter C. The validity of two versions of the GHQ in the WHO study of mental illness in general health care. Psychol Med. 1997;27:191-7.

45. Goodwin L, Ben-Zion I, Fear NT, Hotopf M, Stansfeld SA, Wessely S. Are reports of psychological stress higher in occupational studies? A systematic review across occupational and population based studies. PLoS One. 2013;8(11):e78693.

46. Adlaf EM, Gliksman L, Demers A, Newton-Taylor B. The prevalence of elevated psychological distress among Canadian undergraduates: findings from the 1998 Canadian Campus Survey. J Am Coll Health. 2001;50:67-72.

47. Firth J. Levels and sources of stress in medical students. Br Med J. 1986;292:1177-80.

48. Gorter R, Freeman R, Hammen S, Murtomaa H, Blinkhorn A, Humphris G. Psychological stress and health in undergraduate dental students: fifth year outcomes compared with first year baseline results from five European dental schools. Eur J Dent Educ. 2008;12:61-8.

49. Aalto A-M, Elovainio M, Kivimäki M, Uutela A, Pirkola S. The Beck Depression Inventory and General Health Questionnaire as measures of depression in the general population: a validation study using the Composite International Diagnostic Interview as the gold standard. Psych Res. 2012;197:163-71.

50. Goldberg DP, Oldehinkel T, Ormel J. Why GHQ threshold varies from one place to another. Psychol Med. 1998;28:915-21.

51. Cohen J. A power primer. Psychol Bull. 1992;112:155-9.

52. World Health Organization. Mental Health Action Plan 2013-2020. Geneva: World Health Organization; 2013.

53. Steel Z, Marnane C, Iranpour C, Chey T, Jackson JW, Patel V, Silove D. The global prevalence of common mental disorders: a systematic review and meta-analysis 1980-2013. Int J Epidemiol. 2014;43:476-93.

54. Bonsaksen T, Heir T, Ekeberg $\varnothing$, Grimholt TK, Lerdal A, Skogstad L, Schou-Bredal I. Self-evaluated anxiety in the Norwegian population: Prevalence and associated factors. Arch Public Health. 2019;77:10.

55. Bonsaksen T, Grimholt TK, Skogstad L, Lerdal A, Ekeberg $\varnothing$, Heir T, Schou-Bredal I. Self-diagnosed depression in the Norwegian general population - associations with neuroticism, extraversion, optimism, and general self-efficacy. BMC Public Health. 2018;18:1076.

56. Endsley P, Weobong B, Nadkarni A. The psychometric properties of GHQ for detecting common mental disorder among community dwelling men in Goa, India. Asian J Psych. 2017;28:106-10. 
57. Reuter K, Härter M. Screening for mental disorders in cancer patients - discriminant validity of HADS and GHQ-12 assessed by standardized clinical interview. Int J Methods Psychiatr Res. 2001;10:8696.

58. Elo A-L, Dallner M, Gamberale F, Hottinen V, KnardahI S, Lindström K, Skogstad A, Ørhede E. Validation of the Nordic Questionnaire for Psychological and Social Factors at Work-QPSNordic. In: Innovative theories, tools, and practices in work and organizational psychology. Ashland: Hogrefe \& Huber Publishers; 2000. pp. 47-57.

59. Deci EL, Ryan RM Efficacy, agency, and self-esteem. In: Human Autonomy: the basis for true selfesteem. edn. Edited by Kernis MH. New York, NY: Plenum; 1995: 31-39.

60. Ferris DL, Lian H, Brown DJ, Pang FXJ, Keeping LM. Self-esteem and job performance: the moderating role of self-esteem contingencies. Personnel Psychol. 2010;63:561-93.

61. Crocker J, Wolfe CT. Contingencies of self-worth. Psychol Rev. 2001;108:593-623.

\section{Tables}

Table 1

Characteristics of the sample and of each of the four professional groups 


\begin{tabular}{|c|c|c|c|c|c|c|}
\hline Variables & $\begin{array}{l}\text { Total } \\
\text { sample }\end{array}$ & Nurses & $\begin{array}{l}\text { Occup. } \\
\text { therapists }\end{array}$ & Physiotherapists & $\begin{array}{l}\text { Social } \\
\text { workers }\end{array}$ & $p$ \\
\hline Sociodemographics & $M(S D)$ & $M(S D)$ & $M(S D)$ & $M(S D)$ & $M(S D)$ & \\
\hline Age (years) & $\begin{array}{l}34.4 \\
(6.8)\end{array}$ & $\begin{array}{l}34.1 \\
(6.2)\end{array}$ & 33.7 (6.7) & $31.8(3.3)$ & $\begin{array}{l}36.8 \\
(8.7)\end{array}$ & $<.001$ \\
\hline Gender & $n(\%)$ & $n(\%)$ & $n(\%)$ & $n(\%)$ & $n(\%)$ & \\
\hline Male & $\begin{array}{l}113 \\
(13.2)\end{array}$ & $\begin{array}{l}32 \\
(8.3)\end{array}$ & $13(15.5)$ & $38(24.2)$ & $\begin{array}{l}30 \\
(13.1)\end{array}$ & $\begin{array}{l}< \\
0.001\end{array}$ \\
\hline Female & $\begin{array}{l}743 \\
(86.8)\end{array}$ & $\begin{array}{l}354 \\
(91.7)\end{array}$ & 71 (84.5) & $119(75.8)$ & $\begin{array}{l}199 \\
(86.9)\end{array}$ & \\
\hline $\begin{array}{l}\text { Work environment } \\
\text { factors }\end{array}$ & $M(S D)$ & $M(S D)$ & $M(S D)$ & $M(S D)$ & $M(S D)$ & \\
\hline Demands & $\begin{array}{l}13.4 \\
(2.6)\end{array}$ & $\begin{array}{l}14.1 \\
(2.6)\end{array}$ & $12.4(2.6)$ & $12.3(2.1)$ & $\begin{array}{l}13.5 \\
(2.7)\end{array}$ & $<.001$ \\
\hline Control & $\begin{array}{l}26.9 \\
(3.3)\end{array}$ & $\begin{array}{l}26.0 \\
(3.3)\end{array}$ & 27.1 (3.0) & $27.9(3.0)$ & $\begin{array}{l}27.6 \\
(3.3)\end{array}$ & $\begin{array}{l}<.001 \\
0.01\end{array}$ \\
\hline Support & $\begin{array}{l}12.4 \\
(2.0)\end{array}$ & $\begin{array}{l}12.2 \\
(2.0)\end{array}$ & $12.5(1.8)$ & $12.8(1.7)$ & $\begin{array}{l}12.4 \\
(2.2)\end{array}$ & $\begin{array}{l}< \\
0.05\end{array}$ \\
\hline Work engagement & $M(S D)$ & $M(S D)$ & $M(S D)$ & $M(S D)$ & $M(S D)$ & \\
\hline Job involvement & $\begin{array}{l}16.1 \\
(2.8)\end{array}$ & $\begin{array}{l}16.1 \\
(2.9)\end{array}$ & $16.2(2.7)$ & $16.3(2.7)$ & $\begin{array}{l}16.0 \\
(2.7)\end{array}$ & 0.70 \\
\hline Job satisfaction & $\begin{array}{l}17.8 \\
(4.0)\end{array}$ & $\begin{array}{l}17.9 \\
(3.9)\end{array}$ & $18.6(3.9)$ & $17.4(4.0)$ & $\begin{array}{l}17.6 \\
(3.9)\end{array}$ & 0.19 \\
\hline $\begin{array}{l}\text { Psychological work } \\
\text { factors }\end{array}$ & $M(S D)$ & $M(S D)$ & $M(S D)$ & $M(S D)$ & $M(S D)$ & \\
\hline $\begin{array}{l}\text { Work-home } \\
\text { interaction }\end{array}$ & $2.2(0.8)$ & $\begin{array}{l}2.2 \\
(0.8)\end{array}$ & $2.2(0.7)$ & $2.2(0.8)$ & $2.2(0.8)$ & 0.63 \\
\hline Coping in the job & $4.0(0.5)$ & $\begin{array}{l}4.1 \\
(0.5)\end{array}$ & $4.0(0.4)$ & $4.0(0.5)$ & $4.0(0.5)$ & 0.10 \\
\hline Collaboration & $1.7(2.7)$ & $\begin{array}{l}1.7 \\
(0.6)\end{array}$ & $1.7(0.6)$ & $1.7(0.7)$ & $1.7(0.6)$ & 0.77 \\
\hline Mental health & $M(S D)$ & $M(S D)$ & $M(S D)$ & $M(S D)$ & $M(S D)$ & \\
\hline \multirow[t]{2}{*}{ GHQ score } & $\begin{array}{l}10.6 \\
(4.6)\end{array}$ & $\begin{array}{l}10.7 \\
(4.6)\end{array}$ & $11.0(4.3)$ & $10.0(4.0)$ & $\begin{array}{l}10.7 \\
(4.9)\end{array}$ & 0.27 \\
\hline & $n(\%)$ & $n(\%)$ & $n(\%)$ & $n(\%)$ & $n(\%)$ & \\
\hline $\begin{array}{l}\text { GHQ case-level } \\
\text { score }\end{array}$ & $\begin{array}{l}147 \\
(17.2)\end{array}$ & $\begin{array}{l}65 \\
(16.8)\end{array}$ & $14(16.7)$ & $25(15.9)$ & $\begin{array}{l}43 \\
(18.8)\end{array}$ & 0.90 \\
\hline
\end{tabular}


Note. Work environment factors are measured with the Job Demand Control questionnaire. Work engagement is measured with the Job Involvement questionnaire and Work Orientation measure. Psychological work factors are measured with QPS Nordic. Mental health is measured with the General Health Questionnaire. Statistical tests of group differences are ANOVA F-test (continuous variables) and Chi-Square tests (categorical variables).

Table 2

Associations with mental health (GHQ ratings) in the sample and in each of the four professional groups

\begin{tabular}{|c|c|c|c|c|c|}
\hline & $\begin{array}{l}\text { Total } \\
\text { sample }\end{array}$ & Nurses & $\begin{array}{l}\text { Occup. } \\
\text { therapists }\end{array}$ & Physiotherapists & $\begin{array}{l}\text { Social } \\
\text { workers }\end{array}$ \\
\hline & $\beta$ & $\beta$ & $\beta$ & $\beta$ & $\beta$ \\
\hline \multicolumn{6}{|l|}{$\begin{array}{l}\text { Work environment } \\
\text { factors }\end{array}$} \\
\hline Control & 0.01 & -0.02 & -0.14 & 0.11 & 0.05 \\
\hline Demands & $0.09 *$ & 0.04 & $0.28 *$ & -0.08 & $0.18^{*}$ \\
\hline Support & -0.11 ** & -0.10 & 0.04 & -0.03 & $-0.24^{\star *}$ \\
\hline $\mathrm{R}^{2}$ change & $7.8 \%$ & $6.6 \%$ & $18.1 \%$ & $1.4 \%$ & $16.8 \%$ \\
\hline \multicolumn{6}{|l|}{ Work engagement } \\
\hline Job satisfaction & $0.10 *$ & 0.11 & 0.09 & 0.07 & 0.10 \\
\hline $\mathrm{R}^{2}$ change & $1.6 \%$ & $1.4 \%$ & $0.4 \%$ & $2.0 \%$ & $0.9 \%$ \\
\hline \multicolumn{6}{|l|}{$\begin{array}{l}\text { Psychological work } \\
\text { factors }\end{array}$} \\
\hline Work-home interaction & 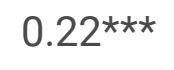 & $0.22^{\star \star \star}$ & $0.37 \star \star$ & $0.29 \star \star$ & 0.11 \\
\hline Coping in the job & $-0.15^{\star \star \star}$ & $-0.16^{\star \star}$ & -0.06 & $-0.27 \star \star$ & -0.05 \\
\hline Collaboration & 0.05 & 0.05 & 0.10 & 0.11 & 0.06 \\
\hline $\mathrm{R}^{2}$ change & $7.7 \%$ & $8.0 \%$ & $13.5 \%$ & $17.9 \%$ & $1.9 \%$ \\
\hline $\begin{array}{l}\text { Total explained } \\
\text { variance }\end{array}$ & $17.1 \%$ & $16.0 \%$ & $31.9 \%$ & $21.4 \%$ & $19.6 \%$ \\
\hline
\end{tabular}

Note. Mental health is measured with the General Health Questionnaire. Work environment factors are measured with the Job Demand Control questionnaire. Work engagement is measured with Work 
Orientation measure. Psychological work factors are measured with QPS Nordic. Table content is standardized $\beta$ values taken from hierarchical multiple linear regression analyses.

${ }^{*} p<0.05$

$\star \star p<0.01$

$\star \star \star * p<0.001$

\section{Table 3}

Associations with case-level psychological distress (GHQ ratings $\geq 4$ ) in the sample and in each of the four professional groups

\begin{tabular}{|c|c|c|c|c|c|}
\hline & Total sample & Nurses & $\begin{array}{l}\text { Occup. } \\
\text { therapists }\end{array}$ & Physiotherapists & $\begin{array}{l}\text { Social } \\
\text { workers }\end{array}$ \\
\hline & OR (95 \% Cl) & OR (95 \% Cl) & OR (95 \% Cl) & OR $(95 \% \mathrm{Cl})$ & $\begin{array}{l}\mathrm{OR}(95 \\
\% \mathrm{Cl})\end{array}$ \\
\hline \multicolumn{6}{|c|}{$\begin{array}{l}\text { Work environment } \\
\text { factors }\end{array}$} \\
\hline Demands & $\begin{array}{l}1.09 *(1.01- \\
1.18)\end{array}$ & $\begin{array}{l}1.12(0.99- \\
1.27)\end{array}$ & $\begin{array}{l}1.18(0.89- \\
1.56)\end{array}$ & $0.86(0.66-1.12)$ & $\begin{array}{l}1.18^{*} \\
(1.02- \\
1.37)\end{array}$ \\
\hline Support & $\begin{array}{l}0.98(0.88- \\
1.09)\end{array}$ & $\begin{array}{l}0.94(0.80- \\
1.10)\end{array}$ & $\begin{array}{l}0.99(0.67- \\
1.44)\end{array}$ & $1.15(0.86-1.53)$ & $\begin{array}{l}0.92 \\
(0.75- \\
1.13\end{array}$ \\
\hline \multicolumn{6}{|l|}{ Work engagement } \\
\hline Job satisfaction & $\begin{array}{l}1.10 \star \star \star \\
(1.04-1.16)\end{array}$ & $\begin{array}{l}1.11 *(1.02- \\
1.20)\end{array}$ & $\begin{array}{l}1.16(0.98- \\
1.38)\end{array}$ & $1.07(0.95-1.21)$ & $\begin{array}{l}1.07 \\
(0.96- \\
1.19)\end{array}$ \\
\hline \multicolumn{6}{|c|}{$\begin{array}{l}\text { Psychological work } \\
\text { factors }\end{array}$} \\
\hline $\begin{array}{l}\text { Work-home } \\
\text { interaction }\end{array}$ & $\begin{array}{l}2.07 \star \star \star \\
(1.57-2.74)\end{array}$ & $\begin{array}{l}1.95^{\star \star}(1.30- \\
2.94)\end{array}$ & $\begin{array}{l}5.06 * * \\
15.45)\end{array}$ & $\begin{array}{l}2.62^{\star \star}(1.34- \\
5.11)\end{array}$ & $\begin{array}{l}1.57 \\
(0.91- \\
2.70)\end{array}$ \\
\hline Nagelkerke $\mathrm{R}^{2}$ & $13.6 \%$ & $15.3 \%$ & $32.4 \%$ & $13.3 \%$ & $14.3 \%$ \\
\hline (Cox Snell R²) & $(8.2 \%)$ & $(9.0 \%)$ & $(20.6 \%)$ & $(7.8 \%)$ & $(8.9 \%)$ \\
\hline
\end{tabular}


Note. Psychological distress is measured with the General Health Questionnaire. Work environment factors are measured with the Job Demand Control questionnaire. Work engagement is measured with the Work Orientation measure. Psychological work factors are measured with QPS Nordic. Table content is $\mathrm{OR}(95 \% \mathrm{Cl})$ taken from multiple logistic regression analyses, adjusted for all employed variables.

${ }^{*} p<0.05$

$\star * p<0.01$

$\star \star \star p<0.01$ 